\title{
The Effectiveness of a Structured Remediation Program to Pass the NCLEX-RN Examination
}

\author{
Fran Cherkis, Annemarie Rosciano \\ Farmingdale State College, New York, USA \\ Email: cherkif@farmingdale.edu, rosciaa@farmingdale.edu
}

Received 2 March 2015; accepted 15 March 2015; published 20 March 2015

Copyright (C) 2015 by authors and Scientific Research Publishing Inc.

This work is licensed under the Creative Commons Attribution International License (CC BY).

http://creativecommons.org/licenses/by/4.0/

c) (i) Open Access

\begin{abstract}
The National Council Licensure Examination for Registered Nurses (NCLEX-RN) has been the standard by which all undergraduate nursing programs are judged for program effectiveness. Consistent patterns of low pass rates can have serious implications for the academic institution, the nursing program, the nursing faculty, the program graduates, and the community at large. Preparing undergraduate nursing students for licensure is a major concern for undergraduate nursing faculty. Present pass rates for the graduate nursing baccalaureate students at a state university are currently below the national average. To address this problem, these researchers have identified interventions that predict success on the NCLEX-RN examination. The implementation of a five week online NCLEX-RN review course in conjunction with three workshops taught and designed by these researchers is used to increase the pass rate on the NCLEX-RN exam. The goal of the implementation of this assessment project is to provide the nursing student with the necessary tools to be successful on the NCLEX-RN. Furthermore, findings from this project have the potential to identify areas for the improvement in the nursing curriculum as well as the increase of the nursing program's NCLEX-RN pass rate.
\end{abstract}

\section{Keywords}

Nursing Students, NCLEX-RN, Remediation, Pass Rates, NCSBN Tutorials

\section{Introduction}

Nursing faculty is continuously motivated to improve the National Council Licensure Examination for Registered Nurses (NCLEX-RN) pass rates for nursing students. Successful completion of a nursing program and passing the 
NCLEX-RN high stakes exam is critical. Validation of nursing students' competence in theoretical and practical learning is evident as a result of high NCLEX-RN pass rates. NCLEX-RN pass rates are an index of nursing programs effectiveness. Nursing program's accreditation status and community reputation are at risk when pass rates do not meet the national benchmark (Langford \& Young, 2013) [1]. There are many reasons that influence the ability of a student to pass the NCLEX-RN such as, grade point average, low scores on standardized testing, and nursing course grades. Nursing programs that graduate small numbers of students have a greater probability of a lower NCLEX-RN pass rate; placing the program at a higher risk for failure. Smaller schools often set higher benchmarks that exceed the national level to counterbalance the potential failure rate associated with smaller numbers of NCLEX-RN exam candidates (Norton et al., 2006) [2].

The purpose of this research was to examine if the implementation of a remediation program increased NLCEX-RN pass rates among 2013 baccalaureate graduate nursing students. Current decreasing trends in the NCLEX-RN pass rates prompted the researchers to design and implement a remediation program that included, a face-to-face review course and the NCSBN Learning Extension online review course for a state university nursing program.

\section{Background}

Nursing students often do well in liberal arts and sciences courses; however these students find it difficult to achieve success in their nursing coursework. This is often a result of the vast amount of information a nursing student is required to know. Students have difficulty discerning what is important to know, creating a situation for failure. Test anxiety and students' time spent on outside employment are identified as major barriers for nursing students to be successful (Carrick, 2011) [3]. Acceptance to a nursing program is often based upon secondary education academic scores and nursing entrance examination scores. However, these students who possess these qualifications have been less successful in nursing programs which is often surprising to the faculty (Carrick, 2011) [3]. These circumstances create a need for faculty to promptly identify these students and engage them in learning activities to improve academic achievement. Faculty can refer students to the college's success centers, encourage them to join study groups, and implement regular face-to-face remediation sessions (Breckenridge, Wolf, \& Roszkowski, 2012) [4]. Students who participate in remediation and continue to struggle are considered a "student at risk for failure" (Carrick, 2011: p. 80) [3]. Faculty often assumes lack of knowledge is the problem with the high risk student. However, research indicates that the problem is not only with the student, but with the faculty's teaching approach (Carrick, 2011) [3].

It is often believed by faculty that students who are unsuccessful in the nursing program are not studying properly. Students feel that they must memorize large amounts of information to learn, therefore students lack the skill to analyze and apply new knowledge (Carrick, 2011) [3]. This strategy is no longer appropriate for students to be successful in current nursing programs. Additionally, passive learning strategies used by faculty do not enhance critical thinking, but is still evident today. To cultivate a deeper understanding of nursing concepts, teaching and learning strategy should be targeted to interactive thinking using active learning and formative assessment (Briggs \& Tang, 2007) [5].

Creating an improved approach to learning is essential for both student and faculty. A variety of active learning strategies have been found to improve NCLEX-RN pass rates including: a) case studies, b) critical thinking exercises, c) completion of NCLEX-RN questions, and d) NCLEX-RN review courses (Norton et al., 2006) [2]. Norton et al. (2006) studied 62 baccalaureate degree nursing students and implemented a face-to-face NCLEXRN review course. The results indicated a $90.48 \%$ pass rate on the NCLEX-RN for these first time test takers, which exceeded this school of nursing's benchmark of $89.8 \%$.

Horton, Pollek, and Hardie (2012) conducted a study among 90 associate degree nursing students because of a drop in NCLEX-RN pass rate. Students who had an overall medical-surgical course score of $76 \%$ participated in a remediation program to prepare for the NCLEX-RN exam. Assessment Technologies Institute (ATI), a standardized NCLEX-RN exam preparation tutorial was the remediation program used. Results indicated that the NCLEX-RN pass rate went from $80 \%$ to $93.6 \%$ after completion of the remediation program.

Young, Rose, \& Wilson (2013) found that self-paced online learning opportunities are preferred by students, are easily accessible, and this type of learning environment is conducive to application of nursing concepts for students. Young et al. (2013) conducted a study among 4000 nursing students from a combination of 137 associate, baccalaureate and diploma schools of nursing that used the Health Education Systems Incorporated (HESI) online 
case studies and the HESI exit exam to prepare students for the NCLEX-RN exam. This remediation intervention resulted in a 3.29 percent increase in the NCLEX-RN pass rate.

Research indicates that grade point average; grades in science courses including pathophysiology, the National League for Nursing (NLN) predictor, and diagnostic exams predict success on the NCLEX-RN exam (Simon, McGinniss, \& Krauss, 2013) [6]. Additionally, a grade of "C" in theory courses (Horton et al., 2012) [7] has been used as an indicator of success on the NCLEX-RN exam. There is limited research about strategies that can improve NCLEX-RN success for students with low grades. Simon et al. (2013) conducted research to determine the relationship between NCLEX-RN readiness and predictor variables among baccalaureate degree nursing students. The results indicated that preclinical science courses and clinical nursing courses are predictors that positively influenced the students' scores on the NLN Diagnostic Readiness Exam taken in preparation for the NCLEX-RN exam.

DiBartolo and Seldomridge's study (as cited in Simon et al., 2013) [6] have identified remediation interventions that have lead to improved pass rates for high risk students are: 1) one-hour faculty and student study periods, 2) biweekly test-taking strategies during the final semester, 3) weekly support group sessions using problem solving scenarios, 4) teacher guided educational sessions, 5) post diagnostic testing, and 6) review courses. However, there are few studies that have reported the outcomes of these efforts.

Researchers have attempted to recognize educational variables such as GPA as a predictor for success; however this remains unclear (Carrick, 2011 [3]; Uyehara, Magnussen, Itano, \& Zhang, 2007 [8]). Test of Essential Academic Skills (TEAS), Assessment Technologies Institute (ATI), (Horton, Pollek, \& Hardie, 2012 [7]), and the NLN Diagnostic Readiness Exam has been used as an assessment to identify high risk students (Carrick, 2011 [3]; Horton et al., 2012 [2]). High risk students who are identified prior to graduation can benefit from strategic learning approaches.

Despite numerous studies, there is no consensus for a consistent set of predictor variables for students to perform successfully on the NCLEX-RN exam (Simon, McGinniss, \& Krauss, 2013 [6]). Early identification of at risk students and the implementation of assessment and standardized test products throughout nursing curricula improve NCLEX-RN exam rates (Carrick, 2011 [3]; Delima, London, \& Mainiere, 2011 [9]). Additionally, it is believed curricula that illustrate the NCLEX-RN test design and use active learning strategies such as, "case studies, using an NCLEX-RN review course and NCLEX-RN question formats in course learning” increases NCLEX-RN pass rates (Carrick, 2011: p. 82 [3]).

\section{Study Aims and Significance}

The NCLEX-RN has been the standard by which all undergraduate nursing programs are judged for effectiveness (Langford \& Young, 2013) [1]. Consistent patterns of low pass rates have serious implications for the academic institution, the nursing program, the nursing faculty, the program graduates, and the community at large (Norton et al., 2006) [2]. Preparing undergraduate nursing students for licensure is a major concern for undergraduate nursing faculty. During 2013, the first time pass rate of the United States educated baccalaureate candidates taking the NCLEX-RN exam was 85.18\% (NCSBN, 2013) [10]. The pass rates for the graduate nursing baccalaureate student at a local state university were below the national average. The aim of this study was to assess if the online NCSBN (National Council State Board of Nursing) peer review course over a five-week period in conjunction with a three-day faculty workshop increased the pass rate on the NCLEX-RN.

\section{Methods}

This study was a non-experimental cross-sectional one-group post-test research design used to determine if the NCSBN Learning Extension online review course and face-to-face workshops increased the NCLEX-RN pass rate for graduate nursing students in May 2013. The workshops included case studies that focused on priority and delegation, critical thinking scenarios, NCLEX-RN review questions with a summative assessment; guest speakers who conducted a review for medical-surgical, mental health, maternal child concepts, pharmacology, and nutrition. The study was conducted at a northeastern state university due to the recent NCLEX-RN pass rate of 72.2\%. This decline triggered a review of available NCLEX-RN preparatory courses and a method to identify at risk nursing students. The remediation program included a structured online National Council of State Board of Nursing (NCSBN) review course and face-to-face workshops conducted simultaneously by the researchers. The researchers received a Title III Student First Grant to cover the cost of the online NCSBN course. The participants 
were required to use the NCSBN online Learning Extension course five days a week for three weeks, and completed a structured study plan as outlined. Printed copies from each of the NCSBN posttests were collected weekly from the students. The participants attended the final program meeting one week after the completion of the remediation program. The purpose of this meeting was to have the participants voluntarily complete an online questionnaire to obtain feedback regarding the remediation program (Appendix 1). This research was approved by the Institutional Review Board of the college where the study was implemented.

\section{Sample}

A purposive sample consisted of 10 baccalaureate degree and 10 associate degree graduating nursing students that achieved a $\mathrm{C}+$ in the final nursing theory course. The majority of the sample size was female and Caucasian with a mean age of 21 . The inclusion criteria incorporated having a score of less than $77 \%$ on the National League for Nursing (NLN) Diagnostic Readiness Exam, which was administered a month prior to graduation.

\section{Implementation of the Study}

Students were invited to attend an informational meeting that included a description of the overall remediation program, each student received a learning contract that included a specific timeline for the completion of the both the online and face-to-face workshop requirements. Based on these criteria a student was given the opportunity to participate or decline. Twenty students agreed to participate and signed the learning contract agreeing to all the guidelines for this NCLEX-RN remediation program, which included:

- maintain required hours to complete all lessons and assignments in the NCSBN review course;

- complete and submit all online posttests and rationales from the NCSBN online tutorials to the researchers weekly;

- submit the online 40 question posttest;

- attendance at the three face to face workshops on campus;

- attend the final review class; and

- complete the program in its entirety without interruption.

The face to face workshops were scheduled once per week for three consecutive weeks, for three hours each. The workshops included interventions such as: 1) case studies, 2) review of delegation, prioritization, and critical thinking exercises, 3) expert faculty provided a review and reinforcement of the concepts that reflected low scores from the NCSBN posttests 4) NCLEX style question bank review, and a 5) student question and answer forum.

\section{Findings}

All 20 students completed the three week program. Upon program completion students were given the option to complete a Survey Monkey ${ }^{\circledR}$ questionnaire and $90 \%$ provided feedback prior to the students taking the NCLEX-RN exam. Sixty percent responded the remediation program was well-structured and pertinent to their learning needs, however they felt that 3 weeks was insufficient time to review all the concepts. Ninety-percent of the students expressed that they were happy they participated in this program, which was not mandated. One hundred percent of respondents reported they would recommend this program to others.

The students' overall NCSBN diagnostic pretest was $46 \%$. Upon completion of the NCSBN review course and the fact-to-face workshop the pass rate of the NCSBN pretest retake increased to a $94 \%$ pass rate. The combination of the simultaneous implementation of the remediation workshops and the NCSBN online review course achieved the desired outcome and increased the overall NCLEX-RN pass rate for the population studied. To the researchers' knowledge, no studies have identified the relationship of the NCSBN online review course as a predictor of success for the NCLEX-RN exam. Before implementing these multiple strategies presented, the annual NCLEXRN pass rate for this nursing school was $72.2 \%$, well below the national benchmark, and post-remediation program the pass rate increased to $90.76 \%$ (Appendix 2).

\section{Discussion}

There are limited studies that have reported the effects of NCLEX-RN preparation interventions. A remediation program using case studies, critical thinking exercises, NCLEX-RN review questions and the NCSBN online Learning Extension course resulted in an increase in the overall NCLEX-RN pass rate. The remediation program 
allowed students to examine, understand, apply and analyze nursing concepts. This intervention strategy enabled faculty to review and reinforce the concepts presented in the NCSBN online Learning Extension course during the weekly face-to-face workshops. In addition, the remediation strategy made it possible for students to recognize strengths and weaknesses.

The approaches used in this study for the remediation of high risk students are consistently supported by Young et al. (2013) [11], Norton et al. (2006); research using review courses is supported by Simon et al. (2013). There is no literature examining the NCSBN Learning Extension online review course or a face to face workshop, independent of each other or simultaneously implemented, and NCLEX-RN success making this research original. Having two methodological interventions simultaneously makes it less likely to identify which of the interventions had the greatest effect on the NCLEX-RN pass rate.

This study supports the idea that NCLEX-RN pass rates are significantly lower when high risk students do not attend a review course. The sample in this study willingly participated in this remediation program and may have been influenced by the fact that the online Learning Extension review course was provided free of charge.

Although the researchers were unable to determine which of the remediation programs interventions had the greatest influence on the NCLEX-RN pass rate, the final nursing course grade of C+ and an NLN Diagnostic Exam below $80 \%$ were used as indicators to identify students who were at high risk and in need of remediation.

Many participants did not submit the post NCSBN online Diagnostic Exam; therefore, the researchers were unable to make a comparison between pre and post Diagnostic Exams to determine the effect of this tutorial review course. The researchers were unable to access these exam results because this tutorial is password protected and not accessible to anyone other than the student.

Faculty determined course modification was necessary to enhance success on the NCLEX-RN exam of future senior nursing students. To strengthen the existing nursing curricula and the nursing students' critical thinking and problem solving skills the final senior capstone course was revised to include an adaptive online learning system that includes preparation, assessment and standardized testing.

\section{Limitations and Conclusions}

Remediation should be deliberate and organized, not spontaneous, to address the student at risk for failing the NCELX-RN exam (Giddens, 2009) [12]. High risk students should be identified earlier than the final semester prior to graduation to facilitate remediation to ensure competence for first-time test takers. High risk students should be assessed using nursing course grades commencing with the first semester nursing course.

A limitation of this study was a small sample size that was school specific. Additional research with larger groups would improve the ability to draw conclusions about the effectiveness and the generalizability of the remediation program implemented.

Attendance at the final meeting was poor; therefore the Survey Monkey response rate was limited. In the future, providing an incentive for the students to complete the questionnaire may enhance response rate. To potentially increase the Survey Monkey response rate, it may be beneficial to administer the questionnaire on the final day of the workshop.

Although there are many variables that may have contributed to the increase in the pass rates, this study's findings appear to be a result of this enhance remediation program. Faculty is accountable to prepare students for successful completion of the NCLEX-RN. Nurse educators need to continue to address the problem of NCLEX$\mathrm{RN}$ success in a systematic and efficacious approach. Interventions such as a face to face workshops and an online review course are but one example of the methods used to address the long standing problem of NCLEX$\mathrm{RN}$ first time pass rates.

\section{References}

[1] Langford, R. and Young, A. (2013) Predicting NCLEX-RN Success with the HESI Exit Exam: Eight Validity Study. Journal of Professional Nursing, 29, S5-S9. http://dx.doi.org/10.1016/j.profnurs.2012.06.007

[2] Norton, C.K., Relf, M.V., Cox, C.W., Farley, J., Lachat, M., Tucker, M. and Murray, J. (2006) Ensuring NCLEX-RN Success for First-Time Test-Takers. Journal of Professional Nursing, 22, 322-326. http://dx.doi.org/10.1016/j.profnurs.2005.11.1104

[3] Carrick, J.A. (2011) Student Achievement and NCLEX-RN Success: Problems That Persist. Nursing Education Perspectives, 32, 72-83. http://dx.doi.org/10.5480/1536-5026-32.2.78 
[4] Breckenridge, D.M., Wolf, Z.R. and Roszkowski, M. J. (2012) Risk Assessment Profile and Strategies for Success Instrument: Determining Prelicensure Nursing Student's Risk for Academic Success. Journal of Nursing Education, 51, 160-166. http://dx.doi.org/10.3928/01484834-20120113-03

[5] Briggs, J. and Tang, C. (2007) Teaching for Quality Learning at University. McGraw Hill, New York.

[6] Simon, E.B., McGinniss, S.P. and Krauss, B.J. (2013) Predictor Variables for NCLEX-RN Readiness Exam Performance. Nursing Education Research, 34, 18-24.

[7] Horton, C., Pollek, C. and Hardie, T.L. (2012) The Relationship between Enhanced Remediation and NCLEX Success. Teaching and Learning in Nursing, 7, 146-151. http://dx.doi.org/10.1016/j.teln.2012.06.002

[8] Uyehara, J., Magnussen, L., Itano, J. and Zhang, S. (2007) Facilitating Program and NCLEX-RN Success in a Generic BSN Program. Nurisng Forum, 42, 31-38. http://dx.doi.org/10.1111/j.1744-6198.2007.00063.x

[9] Delima, M., London, L. and Mainiere, E. (2011) Looking at the Past to Change the Future: A Retrospective Study of Associate Degree in Nursing Graduates' National Council Licensure Examination Scores. Teaching and Learning in Nursing, 6, 119-123. http://dx.doi.org/10.1016/j.teln.2011.01.001

[10] National Council of State Boards of Nursing (2014) NCLEX Statistics from NCSBN. https://www.ncsbn.org/Table_of_Pass_Rates_2013.pdf

[11] Young, A., Rose, G. and Wilson, P. (2013) Online Case Studies: HESI Exit Exam Scores and NCLEXRN Outcomes. Journal of Professional Nursing, 29, S17-S21. http://dx.doi.org/10.1016/j.profnurs.2012.06.0

[12] Giddens, J. (2009) Changing Paradigms and Challenging Assumptions: Redefining Quality and NCLEX Pass Rates. Journal of Nursing Education, 48, 123-124. http://dx.doi.org/10.3928/01484834-20090301-04 


\section{Appendix 1}

Table 1. Participant's feedback regarding the remediation program $(\mathrm{n}=\%)$.

\begin{tabular}{|c|c|c|c|c|}
\hline & & Strongly agree & Agree & Disagree \\
\hline 1 & The presenters for the workshop communicated the information clearly. & $40 \%$ & $60 \%$ & 0 \\
\hline 2 & The presenters made the subject matter compelling. & $30 \%$ & $70 \%$ & 0 \\
\hline 3 & The presenters were able to answer questions. & $70 \%$ & $30 \%$ & 0 \\
\hline 4 & The content of the workshop review was presented in a well structured manner. & $50 \%$ & $50 \%$ & 0 \\
\hline 5 & The pace of the workshop review was right for me. & $40 \%$ & $40 \%$ & $20 \%$ \\
\hline 6 & I am happy I decided to participate in this workshop review. & $50 \%$ & $40 \%$ & $10 \%$ \\
\hline 7 & The concepts presented in the workshop review were pertinent. & $50 \%$ & $50 \%$ & 0 \\
\hline 8 & I want to tell others about the workshop review. & $40 \%$ & $60 \%$ & 0 \\
\hline 9 & The handouts/supporting materials were useful. & $40 \%$ & $60 \%$ & 0 \\
\hline 10 & The workshop enhanced my critical thinking skills and knowledge base. & $10 \%$ & $80 \%$ & $10 \%$ \\
\hline 11 & The learning strategies used in the workshop were effective. & $40 \%$ & $60 \%$ & 0 \\
\hline 12 & The online NCSBN review course was easy to access. & $30 \%$ & $60 \%$ & 0 \\
\hline 14 & The online NCSBN review course contains relevant concepts. & $70 \%$ & $30 \%$ & 0 \\
\hline \multirow[t]{2}{*}{15} & The online NCSBN review course timeline is manageable. & 0 & $40 \%$ & $60 \%$ \\
\hline & & Too challenging & Too easy & Manageable \\
\hline \multirow[t]{2}{*}{13} & Was the course too challenging, too easy, or manageable? & $20 \%$ & 0 & $80 \%$ \\
\hline & & Yes & No & $\begin{array}{l}\text { Did not use } \\
\text { the exercise }\end{array}$ \\
\hline 16 & The online NCSBN interactive exercises are useful. & $100 \%$ & 0 & 0 \\
\hline 18 & The NCSBN Diagnostic Pretest was useful. & $100 \%$ & 0 & \\
\hline 20 & The online NCSBN Posttest and rationales were helpful. & $80 \%$ & $10 \%$ & $10 \%$ \\
\hline \multirow[t]{2}{*}{22} & $\begin{array}{l}\text { My score on the NCSBN pretest was markedly improved on the } \\
\text { post-test by the end of the online course. }\end{array}$ & $50 \%$ & 0 & $50 \%$ \\
\hline & & $\begin{array}{l}\text { Answered } \\
\text { question }\end{array}$ & $\begin{array}{l}\text { Skipped } \\
\text { question }\end{array}$ & \# of responses \\
\hline 17 & $\begin{array}{l}\text { Skip this question if you answered YES to question } 16 \text {. Why did you } \\
\text { feel the interactive exercises were not useful? }\end{array}$ & 0 & 10 & 0 \\
\hline 19 & $\begin{array}{l}\text { Skip this question if you answered Yes to question 18. Why did you } \\
\text { feel the NCSBN Diagnostic Pretest is not useful? }\end{array}$ & 0 & 10 & 0 \\
\hline 21 & $\begin{array}{l}\text { Skip this question if you answered yes to question 20. Why do you } \\
\text { feel the NCSBN Posttest and rationales are not useful? }\end{array}$ & 1 & 9 & 1 \\
\hline 23 & $\begin{array}{l}\text { What suggestions do you have for improving this review class? } \\
\text { Please make any comments you feel will be most helpful to us. }\end{array}$ & 6 & 4 & 6 \\
\hline
\end{tabular}

Note: Sample size $=20$. 


\section{Appendix 2}

\section{Table 2. Statistical display of data.}

\begin{tabular}{ccc}
\hline & Student sample size & Percent \\
\hline Total \# students who graduated from the program in 2013. & $n=65$ & $100 \%$ \\
High risk students that met inclusion criteria to participate in the 2013 study. & $n=20$ & $30.76 \%$ \\
Non-high risk: students that did not meet inclusion criteria to participate in the 2013 study. & $n=45$ & $69.24 \%$ \\
First time NCLEX-RN success (in 2013 study). & $n=19$ & $95 \%$ \\
Second time NCLEX-RN success (in 2013 study). & $n=1$ & $100 \%$ \\
First time NCLEX-RN success (not in the 2013 study) & $n=39$ & $84.4 \%$ \\
Second time NCLEX-RN success (not in the 2013 study). & $n=6$ & $100 \%$ \\
NCELX-RN first time pass rate 2013 for graduating class. & $90.76 \%$ \\
\hline
\end{tabular}

